\title{
Identification of Special Talents in Swimming Pool Blitar District Towards PORPROV 2021 East Java
}

\author{
Wing Prasetya Kurniawan¹, Reo Prasetiyo Herpandika², Rendhitya Prima Putra3 ${ }^{3}$ Mokhammad \\ Firdaus ${ }^{4}$, Septyaning Lusianti ${ }^{5}$ \\ 1, 2, 3, 4, 5 Nusantara University PGRI Kediri \\ Email: 1 wingprasetya@unpkediri.ac.id, 2 reoprasetiyo@unpkediri.ac.id, \\ 3rendhitya@webmail.unpkediri.ac.id, 4 m.firdaus@unpkediri.ac.id, 5 Lusi.Septya@unpkdr.ac.id \\ doi https://doi.org/10.36526/gandrung.v1i2.918
}

\begin{abstract}
This special talent identification activity was aimed at Blitar Regency swimming athletes who were registered in the Blitar PRSI Pengcab District with the intention that netted talented athletes to represent Blitar Regency in the PORPROV 2021 event. The method of identifying special swimming sport talent was using the Anthropometry test and the Biomotor swimming component as many as 32 athletes. From the test results, seven male and seven female athletes were selected to be included in the Blitar Regency swimming team. This kind of activity should be carried out routinely, monitoring physical abilities should be carried out every six months and identifying special swimming sports talent is also aimed at junior athletes in the hope that the regeneration of swimming athletes in the Blitar Regency continues.
\end{abstract}

Keyword: Identification, Special Talent, Swimming.

\section{Pendahuluan}

Sesuai dengan UU Nomor 3 Tahun 2005 tentang sistem Keolahragaan Nasional dengan Peraturan Pemerintah yang menyertainya maka upaya pembenahan terhadap pembinaan keolahragaan nasional harus terus dikedepankan. Berbagai elemen bangsa, baik pemerintahan, dunia olahraga, dunia pendidikan, dunia usaha dan indusstri, serta elemen masyarakat lainnya memiliki peran yang sama untuk memajukan prestasi nasional. Pembina olahraga dengan tingkat kompetitif yang tinggi tentu dituntut untuk membina calon-calon atlet berbakat untuk dibina secara intensif dalam iklim pembinaan dan kompetisi yang intensif. Faktor pembinaan sejak dini melalui program pembibitan yang terstruktur dan berkesinambungan dengan konsep yang tepat menjadi sebuah tuntutan pada olahraga prestasi sekarang ini.

Semakin dini seseorang menunjukkan kesesuaian latihan dan kemampuan untuk belajar, maka makin berhasil dalam menyelesaikan program latihan. Sehingga memiliki lebih banyak waktu untuk berlatih sebelum mencapai prestasi puncak. Oleh karena itu, pemanduan bakat merupakan suatu proses penentuan prestasi, dimana seseorang harus memiliki kemampuan tersebut agar dapat mencapai tingkat prestasi optimal. 
GANDRUNG: Jurnal Pengabdian Kepada Masyarakat ISSN: 2721-6136 (Online)

Bakat dapat dimaknai sebagai suatu kelebihan yang dimiliki oleh setiap orang yang secara rutin dilatih dan akan menjadikan seseorang tersebut menjadi orang yang hebat dan memiliki kemampuan tersendiri, sehingga dalam prosesnya menjadi orang yang mandiri dan berbakat. Bakat yang dimiliki seseorang merupakan pembawaan yang terkandung dalam diri. Singgih (Nuruddin, 2012: 40) menyatakan bahwa bakat olahraga merupakan potensi seseorang untuk berprestasi dalam kegiatan olahraga tertentu, karena dalam dirinya terdapat ciri-ciri yang dapat dikembangkan dan diprakondisi dalam menunjang keberhasilan. Salkind dalam wasadi dan mardapi (2016: 99) menyebutkan bahwa bakat adalah perbedaan individu yang ber-kaitan dengan pembelajaran berikutnya da-lam jangka waktu yang sama. Sedangkan menurut Nurkanca dalam Yusfandaria (2019: 62) Bakat adalah suatu kualitas yang Nampak pada tingkah laku manusia pada suat lapangan keahlian tertentu seperti music, seni mengarang, kecakapan dalam matematika, keahlian dalam bidang mesin, atau keahlian-keahlian lainnya.

Lumintuarso (2006: 12) menyatakan bahwa bakat adalah kemampuan untuk terbentuknya keahlian atau keberhasilan orang atau atlet dalam melakukan sesuatu. Menurut Irianto (2002: 28) mengartikan bakat atau telent sebagai potensi yang dibawa sejak lahir, merupakan pembawaan yang diperoleh secara genetik dari faktor keturunan. Dalam olahraga, identifikasi bakat menggambarkan proses mengenali dan memilih calon atlet yang menunjukkan potensi dirinya supaya mampu bersaing dalam kompetisi tingkat nasional maupun internasional (Baker, 2012: 4).

Berdasarkan beberapa pendapat di atas dapat disimpulkan bahwa bakat adalah potensi yang dimiliki seseorang untuk berprestasi dalam kegiatan olahraga tertentu, karena dalam dirinya terdapat ciriciri yang dapat dikembangkan dan prakondisi yang menunjang keberhasilan dalam olahraga. Tahapan yang paling penting dalam menciptakan pondasi keberhasilan sistem pembinaan prestasi olahraga yaitu dengan pemanduan bakat yang dilakukan dari atlet usia dini. menurut Baker (2012: 5) menyatakan bahwa keberhasilan dari pengembangan bakat adalah tersedianya para ahli dan penyediaan sarana dan prasarana bagi atlet sehingga diharapkan mampu mempercepat proses latihan yang kedepannya dapat mempengaruhi prestasi atlet.

Upaya untuk memilah dan memilih calon atlet berbakat olahraga harus mendapat perhatian dari para pembina/pelatih olahraga. Permasalahannya adalah bahwa di Kabupaten Blitar masih terbatas sekali tes yang dapat diakses untuk melakukan seleksi atau pemanduan bakat olahraga. Hal ini dapat dilihat pada cabang olahraga renang kalau dilakukan pemassalan, pencarian bakat dan pembinaan dengan baik dapat menjadi cabang olahraga andalan bagi Tim renang Kabupaten Blitar, Perkumpulan Renang yang terdaftar di Pengcab PRSI Kabupaten Blitar Sebanyak 6 Klub, Akan tetapi dilihat dari 
GANDRUNG: Jurnal Pengabdian Kepada Masyarakat ISSN: 2721-6136 (Online)

perolehan medali berangkat dari PORPROV ke-1 sampai PORPROV ke-6 belum pernah mendapatkan medali.

\section{Metode}

Metode yang digunakan untuk mengidentifikasi bakat istimewa cabor renang dengan PAR (Participatory Action Research) yaitu tes Antropometri dan komponen Biomotor cabor renang. PAR (Participatory Action Research) adalah yaitu metode penelitian aksi partisipatoris, yang bertujuan untuk mengidentifikasi rumusan masalah penelitian berdasarkan kebutuhan dari subyek yang diteliti. Suyanto (2017). Sedangkan menurut Syanas (2019: 234) Participatory Action Research (PAR) merupakan salah satu dari sekumpulan metodologi penelitian (action research, action learning) dan metode lainnya yang menekankan pada bagaimana partisipasi dan kolaborasi dari berbagai pihak dalam mengelola sebuah penelitian action research.

Kegiatan identifiikasi bakat istimewa ini ditujukan kepada atlet renang yang terdaftar dalam Pengcab PRSI Kab.Blitar dengan maksud agar terjaring untuk mewakili Kabupaten Blitar di ajang PORPROV 2021.Jumlah atlet yang mengikuti tes sebanyak 32 orang yang berasal dari 6 klub di Kabupaten Blitar.

Tes yang digunakan yaitu Antropometri dan Komponen Biomotor. APORI (2012: 31) menyimpulkan bahwa Tes Antropometri Meliputi: (1) Tinggi badan dan Berat Badan, (2) Lebar pinggul trochanteric, (3) Lebar bahu, (4) Lebar elbow, (5) Lingkar lengan atas, (6) Lingkar lengan bawah, (7) Lingkar paha, (8) Lebar telapak tangan dan lebar telapak kaki. Sedangkan tes untuk komponen biomotor renang meliputi : (1) Back dan Leg Dynamometer, (2) Push-up, (3) Pull Up, (4) Sit Up, (5) Shoulder range of motion, (6) Angkle range of motion, (7) multi stage fitness test, (8) standing long jump, (9) flexi meter tes, dan (10) tes lari $30 \mathrm{~m}$.

Pelaksanan program identifikasi bakat istimewa cabor renang ini tidak terlepas dari peran dan partisipasi aktif dari Pengcab PRSI Kab.Blitar. Partisipasi dimaksudkan di sini adalah terlibat dalam menyediakan fasilitas tempat kegiatan dan praktek, terlibat dalam penyediaan alat dan bahan tes, keaktifan atlet dalam mengikuti proses identifikasi dari awal sampai akhir. Pelaksanaan program pada tahap ini dilaksanakan 1 hari, untuk kemudian dikaji dan dilakukan pengembangan.

\section{Hasil dan Diskusi}

Berdasarkan hasil tes yang dilakukan menggunakan Antropometri dan Komponen Biomotor terhadap atlet yang terdaftar dalam Pengcab PRSI Kab.Blitar mendapatkan kriteria yang lolos untuk terjaring dalam tim renang Kabupaten Blitar sebanyak tujuh atlet putra dan tujuh atlet putri dari total 
GANDRUNG: Jurnal Pengabdian Kepada Masyarakat ISSN: 2721-6136 (Online)

jumlah seleksi 32 atlet.

Dalam pengembangan bakat ini faktor yang dominan adalah dari perkembangan motorik atlet yang dilihat dari usia permulaan, spesialisasi, dan prestasi puncaknya. Perkembangan adalah proses perubahan kapasitas fungsional atau kemampuan kerja organ tubuh ke arah keadaan yang makin terorganisasi dan terspesialisasi. Makin terorganisasi artinya bahwa organ tubuh makin bisa dikendalikan sesuai dengan kemauan. Makin terspesialisasi artinya bahwa organ tubuh semakin bisa berfungsi sesuai dengan fungsinya masing-masing. Atlet yang berprestasi mengalami pertumbuhan dan perkembangan fisik dan mental secara bersama-sama maupun bergantian dan berkesinambungan. Ketika atlet bertambah tinggi dan besar, sejalan dengan bertambahnya usia maka, kemampuannnya akan meningkat.

Dalam penelitian yang dilakukan departemen kinesiologi di Michigan tentang perkembangan motorik menyatakan bahwa atlet laki-laki yang berusia 5 tahun saat menunjukkan kemampuannya akan terlihat kembali saat atlet tersebut berusia 15 tahun. Hal ini di lihat dari prosentase yang menyatakan bahwa penampilan kemampuan atlet laki-laki pada prosentase $20-40 \%$ sedangkan untuk atlet wanita mempunyai prosentase $40-50 \%$. Pemberian metode latihan yang sama antara atlet laki-laki dan atlet perempuan dari usia 5 tahun sampai usia 15 tahun maka, dapat disimpulkan bahwa penampilan kemampuan antara atlet perempuan akan lebih terlihat dibandingkan pada atlet laki-laki.

Sebagai seorang pelatih sebaiknya mampu mengidentifikasi atletnya dalam salah satu cabang olahraga yang ditekuninya. Kriteria pemilihan seorang atlet bisa ditinjau melalui ciri-ciri atlet karena dalam diri atlet terdapat ciri-ciri yang bisa dikembangkan dan diprakondisi dalam menunjang keberhasilan. (Nurrudin, 2012: 40) menyatakan bahwa ada beberapa ciri pada atlet yang berpotensi terhadap penampilan dan tingkat prestasi meliputi: (a) faktor struktur biologis, (b) faktor sosial, (c) faktor fisiologis, (d) faktor psikologis, (e) faktor kesegaran jasmani, (f) faktor keterampilan, (g) faktor ketajaman panca indera menerima rangsangan secara tepat, (h) faktor jenis kelamin, (i) faktor usia.

Dalam penentuan altet berprestasi perlu diketahui tentang ciri-ciri khusus yang dimiliki. Dengan demikian sifat, kebiasaan dan watak masing-masing kepribadian calon atlet terdeteksi secara lengkap. Pencarian bibit unggul dilaksanakan oleh tim yang terdiri dari tenaga pendidikan jasmani, pelatih, olahraga, psikolog, sosiolog dan antropolog. Sehingga cara pencarian bibit unggul antara lain melalui pendekatan: (a) observasi atau pengamatan, (b) angket dan wawancara, (c) tes pengukuran kemampuan fisik. 
GANDRUNG: Jurnal Pengabdian Kepada Masyarakat ISSN: 2721-6136 (Online)
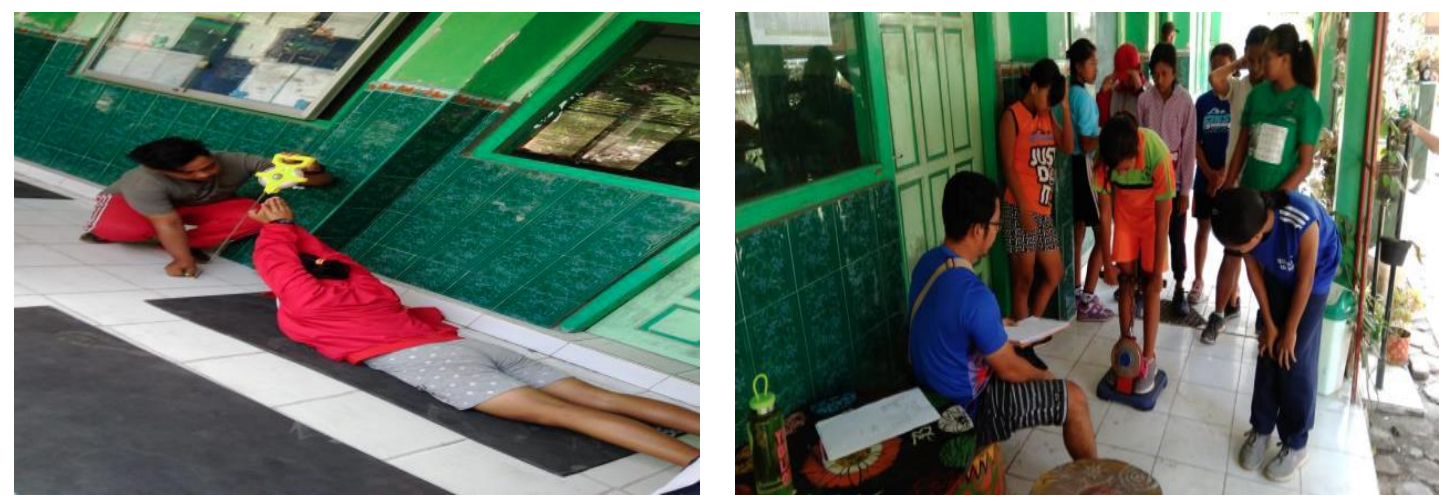

Gambar 1. Pelaksanaan Tes Identifikasi Bakat

\section{Kesimpulan}

Pelaksanaan identifikasi bakat sebelumnya mengalami keterbatasan tes yang dapat diakses untuk melakukan seleksi atau pemanduan bakat olahraga cabor renang Kab. Blitar. Setelah dilakukan pendampingan memanfaatkan Sport Sains menggunakan tes antropometri dan komponen biomotor, dari hasil tes yang telah dilakukan tersaring tujuh atlet laki-laki dan tujuh atlet perempuan yang layak masuk dalam tim renang Kabupaten Blitar. Dengan diadakan identifikasi ini dapat menyaring atlet berbakat dan berpotensi untuk Kabupaten Blitar sehingga mampu bersaing dan berprestasi diajang PORPROV 2021 Jawa Timur.

Kegiatan semacam ini hendaknya dilaksanakan dengan rutin, monitoring kemampuan fisik hendaknya dilakukan enam bulan sekali serta kegiatan identifikasi bakat istimewa cabor renang juga ditujukan kepada atlet junior dengan harapan regenerasi atlet renang Kabupaten Blitar terus ada.

\section{Daftar Referensi}

Baker, J., Steve C., \& Jorg, S. 2012. Talent identification and development in sport: international perspectives. New York: Routledge.

Irianto, J.P. 2002. Dasar kepelatihan. Surat Perjanjian Pelaksanaan Penulisan Diklat, Nomor: 688. a/J. 35. 16/KU/2002.

Lumintuarso, R. 2006. Materi kuliah multilateral. Yogyakarta: FIK UNY.

Nurrudin. 2012. Pengembangan instrumen pemanduan bakat cabang olahraga anggar menuju atlet 2022. Jurnal ilmiah SPIRIT, ISSN; 1411-8319 Volume 12 Nomer. Semarang: Universitas Negeri Semarang.

Supriyanto, A. 2013. Pedoman identifikasi pemanduan bakat istimewa cabang olahraga renang. Yogyakarta: Asosiasi Pelatih Olahraga Indonesia.

Suyanto. 2017. "Membangun Kesadaran Sodaqoh Sampah Sebagai Sebagai Model Pemberdayaan Masyarakat" Dakwah: Jurnal Perberdayaan Masyarakat, Volume 1 No 2 (2017): 213-226, 
GANDRUNG: Jurnal Pengabdian Kepada Masyarakat ISSN: 2721-6136 (Online)

diakses 24 Juni 2020. http://ejournal.uin-suka.ac.id/dakwah/JPMl/article/view/1171.

Syanas dkk. 2019. "Metode Pertanyaan Socrates Dalam Pembelajaran Materi Koloid Menggunakan Participatory Action Research (PAR)" JKPK: Jurnal Kimia dan Pendidikan Kimia, Volume 4 No 3 (2019): 232-240, diakses 5 Juni 2020. https://jurnal.uns.ac.id/jkpk/article/view/38108/25544

Undang-undang Republik Indonesia Nomor 3 Tahun 2005 tentang sistem Keolahragaan Nasional, diakses 15 Juni 2020. http://www.dpr.go.id/dokjdih/document/uu/45.pdf.

Yusfandaria. 2019. "Upaya Mengembangkan Kemampuan Bakat Melalui Layanan Bimbingan Karir Dengan Strategi Problem Solving Peserta Didik Kelas X Ips.2 Sma Negeri 18 Palembang" JUANG: Jurnal Wahana Konseling, Volume 2 No. 1 (Maret 2019): 60-69, diakses 12 Juni 2020. https://jurnal.univpgri-palembang.ac.id/index.php/juang/article/download/2756/2622

Warsidi dan Mardapi. 2016. Pengembangan Instrumen Bakat Keguruan" UNY :Jurnal Penelitian dan Evaluasi Pendidikan, Volume 20 No 1 (Juni 2016) :98-110, diakses 3 Juni 2020. https://journal.uny.ac.id/index.php/jpep/article/download/7519/7772. 